\title{
Experimental study on Green Water in Regular Waves
}

\author{
Ju-Chull Han* $\cdot$ Seung-Keun Lee** $\cdot$ Gyoung-Woo Lee*** \\ *Department of Naval Architecture and Ocean Engineering, Pusan National University, Pusan, 609-735, Korea \\ **Department of Naval Architecture and Ocean Engineering, Pusan National University, Pusan, 609-735, Korea \\ ***:Division of Ocean System Engineering, Mokpo National Maritime University, Mokpo, 530-729, Korea
}

\begin{abstract}
FPSOS are commonly proposed and used for offshore oil production. Due to the fundamental requirement of FPSOS to remain moored at their location, they are unable to avoid severe weather. FPSOs normally operate head to the weather, and sensitive equipment located near the bow will be susceptible to green water damage. Damage may occur to both equipment and superstructure, with resulting risk to personnel. To initially access green water is allowed by the physical understanding of green water events. In this paper the main focus is put on the physical phenomena of green water accounted for with the tested data in regular waves.
\end{abstract}

Key words : green water, FPSO, dam-breaking

\section{Introduction}

Floating Production Storage and Offloading Systems (FPSOs) provide an attractive option for oil production facilities for marginal and small fields in remote waters and are being deployed in almost every part of the world.

They are generally designed to weathervane to the prevailing conditions, often using a turret mooring system, and in harsh environments can experience large steep head seas. Green water is unbroken waves overtopping the bow, side or stern of a vessel, often in the form of shallow water waves washing along and across the deck.

Green water on the deck of FPSOs can cause damage to the sensitive equipment at the bow, such as fluid swivel, piping and turret structure, as well as to the bow itself. In a study examining the susceptibility of FPSOs and FSUs to green water incidents in the North Sea fifteen floaters in UK waters and five in the Norwegian sector were surveyed. The study showed that over a period of about five years half of the installations had been affected by wave damage. Seventeen green water and two wave slam incidents were identified at twelve installations.

The study also revealed that the incidents had generally occurred in wave conditions much less than their design maximums (Morris et al., 2000). Some examples from water on the deck events on Norwegian production ships have been given in Ersdal \& Kvitrud (2000), while severe bow damage has been reported on a UK vessel West of Shetland (MacGregor et al., 2000).

In this paper, the set-up of model tests were described and the typical sequence of green water events was fully explained with the experimental results.

\section{Model tests}

Tests were carried out in the ocean wave basin at the Norwegian Marine Technology Research Institute A/S (Marintek). The basin shown in Fig.1 is $80 \mathrm{~m}$ long by $50 \mathrm{~m}$ wide with an adjustable water depth of up to $10 \mathrm{~m}$. For the present experiments the water depth was set to $1.53 \mathrm{~m}$.

The bow of the model depicted in Fig. 2 and Table 1 was instrumented so that the profiles of the waves in its vicinity and of the water on deck could be measured. The waves were recorded using 4 relative- ${ }^{-}$wave elevation gages fixed to the front of the bow and a 10-staff wave array was installed in order to record the water flow on deck. The impact of green water hitting the deckhouse was measured using three load panels, each measuring the integrated force on an area $0.05 \mathrm{~m}$ by $0.05 \mathrm{~m}$. The force sensors were designed to be particularly stiff, with natural periods $175 \mathrm{~Hz}$ (full scale, in water).

The model was moored at the centre of the basin with a realistic10-line catenary system. Vessel motions in 6 DOF were measured by an optical recording system with accuracy better than $0.001 \mathrm{~m}$. The sampling rate was $647 \mathrm{~Hz}$ (full scale) for the load and pressure measurements and 11 $\mathrm{Hz}$ (full scale) for the other channels. Continuous video recordings of all tests were made with a 4-camera high-resolution system, including two cameras from the side, one viewing forward from the top of the deckhouse, and one viewing downwards on the front deck.

* Corresponding Author : Ju-Chull Han, louisdior@hanmail.net, 011-858-6937 
A series of experiments were run in regular waves for periods from 1.3 to $2.0 \mathrm{sec}$ with wave heights between 0.2 to $0.5 \mathrm{~m}$, as indicated in Table 2. The waves with periods of around $1.5 \mathrm{sec}$ are of a similar magnitude to the ship length.

The model was constructed with a removable bulwark instrumented with five load panels. The bulwark was retained for the irregular sea test, and then tested for the same conditions without them. The regular wave tests were run without bulwarks since they were intended for producing results for validating the theoretical model, which did not include bulwarks.

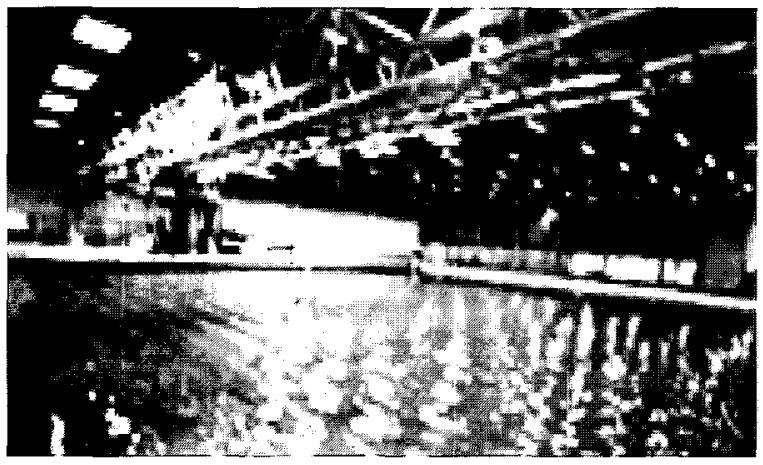

Fig. 1 Ocean wave basin

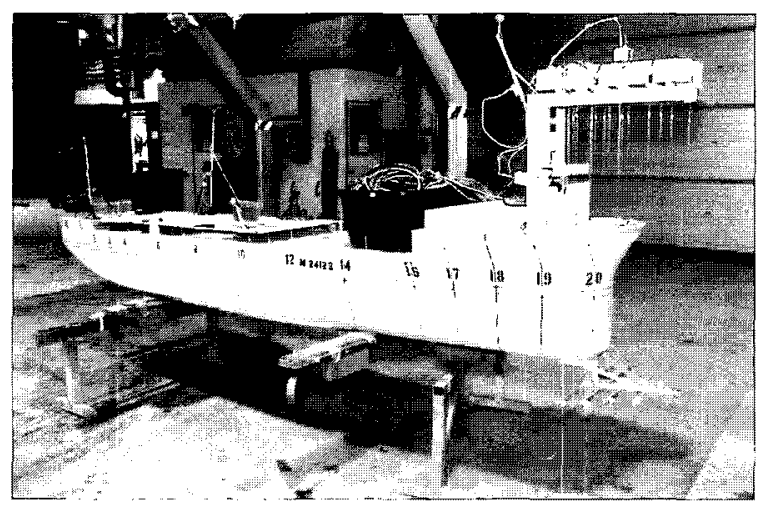

Fig. 2 Model tested

Table 1 Principal dimensions and particulars

\begin{tabular}{|l|c|c|}
\hline & Model & Full scale \\
\hline scale Ratio & \multicolumn{2}{|c|}{$1 / 55$} \\
\hline length (Lpp) & $3.642 \mathrm{~m}$ & $200 \mathrm{~m}$ \\
\hline breadth & $0.695 \mathrm{~m}$ & $38 \mathrm{~m}$ \\
\hline depth & $0.524 \mathrm{~m}$ & $29 \mathrm{~m}$ \\
\hline draft & $0.291 \mathrm{~m}$ & $16 \mathrm{~m}$ \\
\hline displacement & $635 \mathrm{~kg}$ & $170,500 \mathrm{t}$ \\
\hline KG & $0.273 \mathrm{~m}$ & $15 \mathrm{~m}$ \\
\hline GM & $0.031 \mathrm{~m}$ & $1.7 \mathrm{~m}$ \\
\hline LCG & $1.736 \mathrm{~m}$ & $95 \mathrm{~m}$ \\
\hline $\mathrm{K}_{\mathrm{w}}$ & $0.933 \mathrm{~m}$ & $51 \mathrm{~m}$ \\
\hline
\end{tabular}

Table 2 Regular waves tested in model scale (wave heights vs wave periods)

\begin{tabular}{|c|c|c|c|c|}
\hline & $0.2 \mathrm{~m}$ & $0.3 \mathrm{~m}$ & $0.4 \mathrm{~m}$ & $0.5 \mathrm{~m}$ \\
\hline $1.3 \mathrm{sec}$ & $\mathrm{X}$ & $\mathrm{X}$ & & \\
\hline $1.4 \mathrm{sec}$ & $\mathrm{X}$ & $\mathrm{X}$ & & \\
\hline $1.5 \mathrm{sec}$ & $\mathrm{X}$ & $\mathrm{X}$ & & \\
\hline $1.6 \mathrm{sec}$ & $\mathrm{X}$ & $\mathrm{X}$ & $\mathrm{X}$ & \\
\hline $1.7 \mathrm{sec}$ & $\mathrm{X}$ & $\mathrm{X}$ & $\mathrm{X}$ & $\mathrm{X}$ \\
\hline $1.8 \mathrm{sec}$ & $\mathrm{X}$ & $\mathrm{X}$ & $\mathrm{X}$ & $\mathrm{X}$ \\
\hline $1.9 \mathrm{sec}$ & $\mathrm{X}$ & $\mathrm{X}$ & $\mathrm{X}$ & $\mathrm{X}$ \\
\hline $2.0 \mathrm{sec}$ & $\mathrm{X}$ & $\mathrm{X}$ & $\mathrm{X}$ & $\mathrm{X}$ \\
\hline
\end{tabular}

\section{Sequence of green water events}

The commonly recognised types of green water are the dam-breaking type in Fig. 3 and the plunging wave type in Fig. 4. The plunging wave type means a steep, energetic wave may results in special green water events, and the loading is almost independent of the ship shape and is a direct result of the wave crest overtopping the freeboard level. This case was only observed in irregular waves. In this paper only the dam-breaking type is discussed.

The followings are the typical sequence of the dam-breaking type; a) there is a relative motion around the bow between the deformed wave surface and the oscillating ship b) the water above the freeboard level comes onto the deck c) the water then washes along and across the deck in the form of the shallow water wave d) the mass of the water strikes the deck itself, equipments like a deck structure located on the deck.
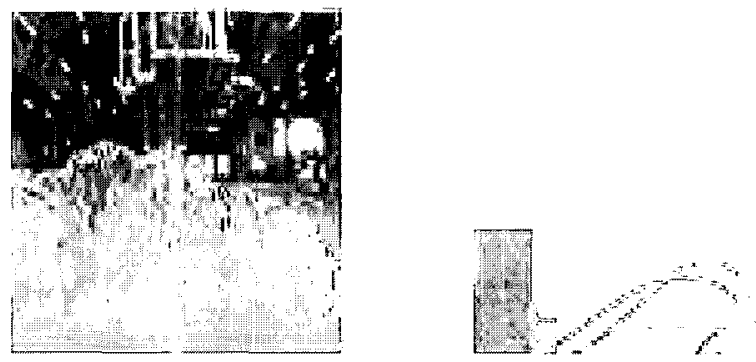

Fig. 3 dam-breaking type water on deck
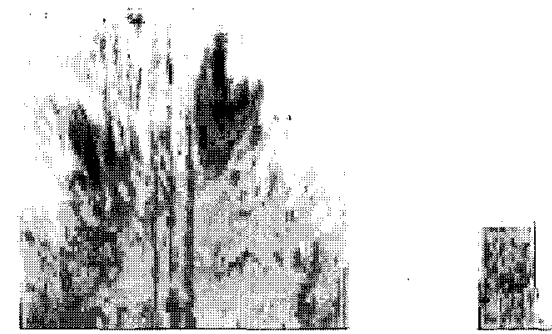

Fig. 4 plunging-wave type water on deck 


\subsection{Relative wave motion}

The relative wave motions around the bow may be seen as the input to the green water problem. The relative wave motion $(\boldsymbol{r})$ is defined as the difference between the local vertical vessel motion ( $z$ : heave+pitch) and the local disturbed wave motion $(\eta)$ according to :

$$
r=z-\left(\eta_{I}+\eta_{R}+\eta_{D}\right)
$$

where

$\eta_{I}$ is the incident wave elevation

$\eta_{R}$ is the radiated wave elevation

$\eta_{D}$ is the diffracted wave elevation

Therefore, the freeboard exceedance $\left(f_{e}\right)$ corresponding to the local freeboard $(f)$ is obtained as

$$
f_{e}=-f-r
$$

As seen in Eq.1, the relative motions are a function of both the ship motions and disturbed wave motions. Fig 5 and 6 illustrates non-linealities of pitch in longer waves, which may be due to the mooring lines or more mass of water on deck than in short waves. The difference of pitch crests of Fig 5 and troughs of Fig 6 shows very marginal.

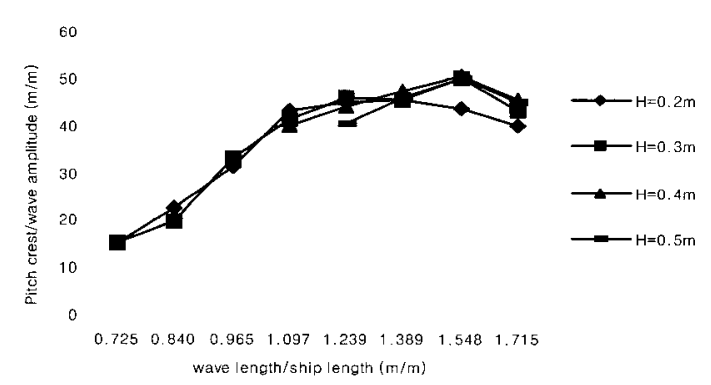

Fig. 5 measured pitch crest (H: wave height)

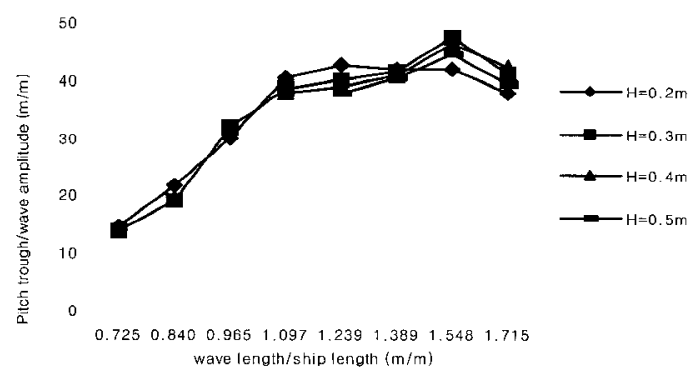

Fig. 6 measured pitch trough

In Fig 7 and 8 crests and troughs of relative wave motion are shown and there are generally higher values in crests compared to corresponding troughs. The radiated and diffracted waves, which account for bow shape like flare angle, may be important inputs to figure out the discrepancy.

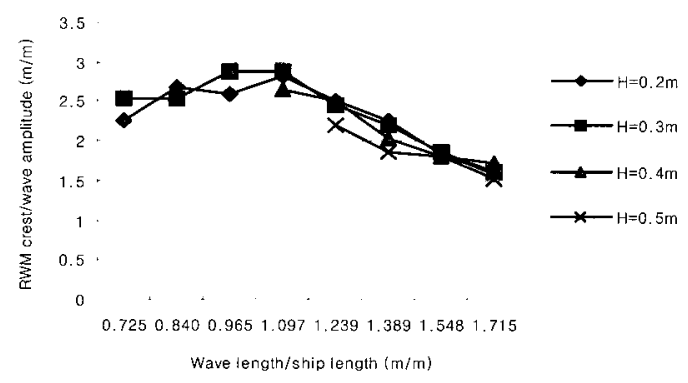

Fig. 7 crest of measured relative wave motion(RWM)

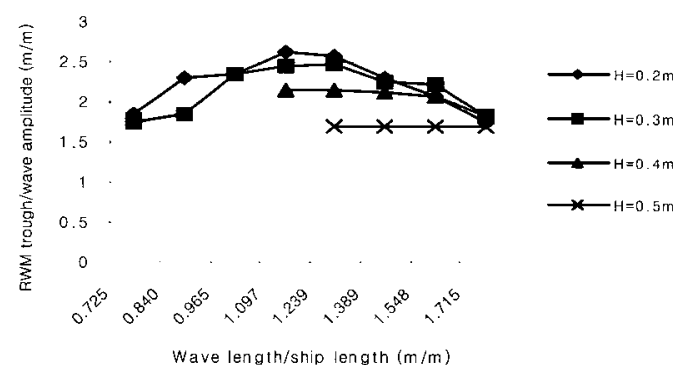

Fig. 8 trough of measured relative wave motion(RWM)

\subsection{Water flow onto deck}

Despite the facts that the ship is moving, the freeboard exceedance is varying in time and the initial velocity of water onto deck is not zero, the clear resemblance between most cases of green water flow onto deck (Fig.9 \& 10) and the theoretical dam-breaking problem in Fig. 8 (see Stoker (1957) for the solution using the characteristic equations) leads to the application of the theory into the green water problem, for example.

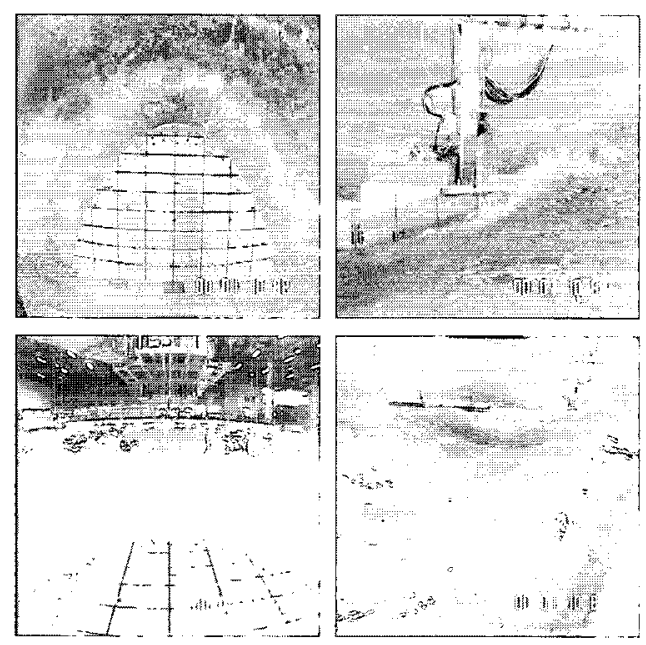

Fig. 9 photos just before the dam-break type water flows onto deck 


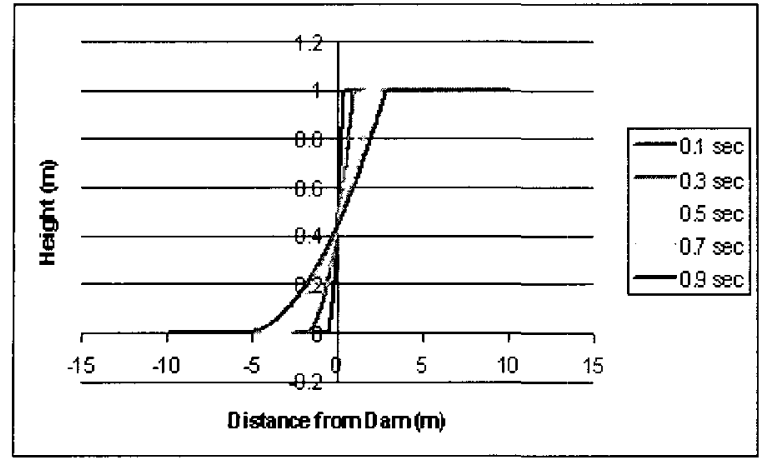

Fig. 10 water contour at different time step according to the theoretical dam-breaking problem

\subsection{Water behavior on deck}

The exact pattern of the water on the deck depends on freeboard exceedance, bow flare angle, shape of the deck in plan view, vessel motions and wave period. Fig 11 and 12 show typical patterns of water elevation on deck in shor: and long wave, respectively. There seems to be a sudden fall-down after time 71.1121 in Fig 11 and to be a smooth flood-in after time 60.2994 in Fig 12, which may be caused by wave steepness. On top of the velocities and pattern of the water on deck, the pressure due to water on deck is also of importance for the design.

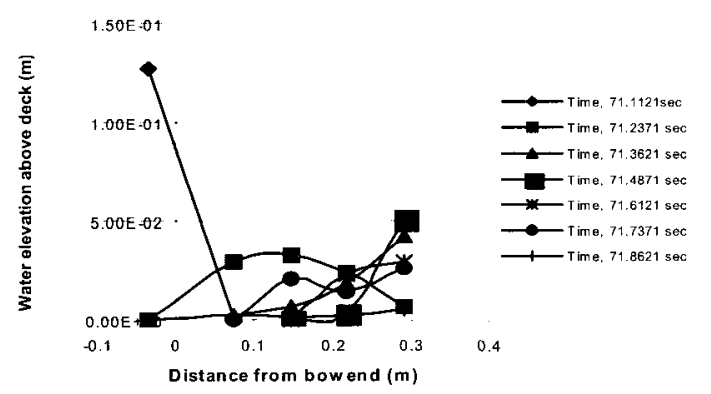

Fig. 11 water elevation on deck in wave period $1.3 \mathrm{~s}$ and wave height $0.3 \mathrm{~m}$

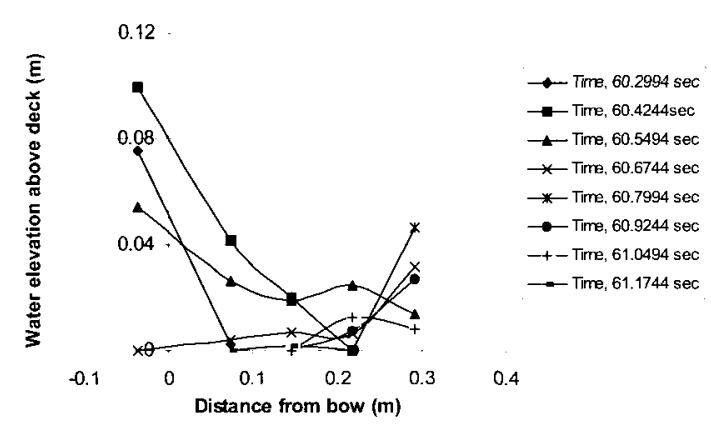

Fig. 12 water elevation on deck in wave period $2.0 \mathrm{~s}$ and wave height $0.5 \mathrm{~m}$
In Fig 13 and 14 phase relationship of green water impact are explained, where we can find the max. of freeboard exceedance is occurring when pitch reaches the lowest point in short wave of Fig 13 or when the bow is moving up back from the lowest point in fig 14 .

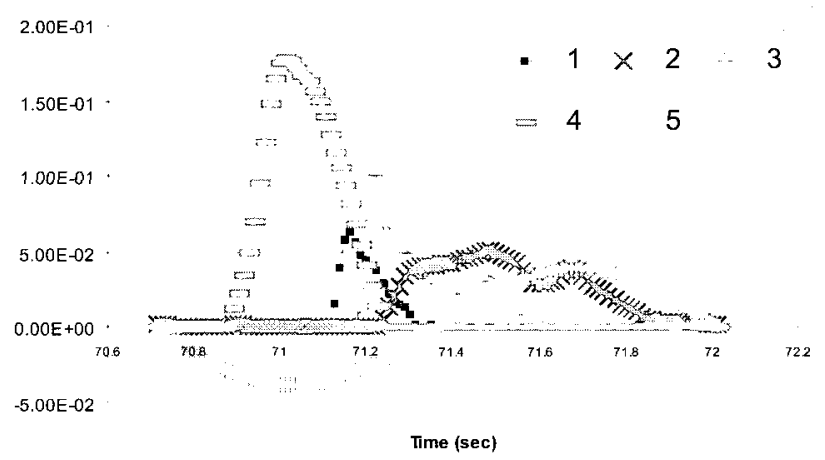

Fig. 13 phase relations of green water impact at the deck structure at wave period $1.3 \mathrm{~s}$ and height $0.3 \mathrm{~m}$ (1 represents water onto deck in $\mathrm{m}, 2$ water height $0.37 \mathrm{~cm}$ from the structure in $\mathrm{m}, 3$ pitch motion in radian, 4 freeboard exceedance in $m, 5$ force at structure in $N / 100$ )

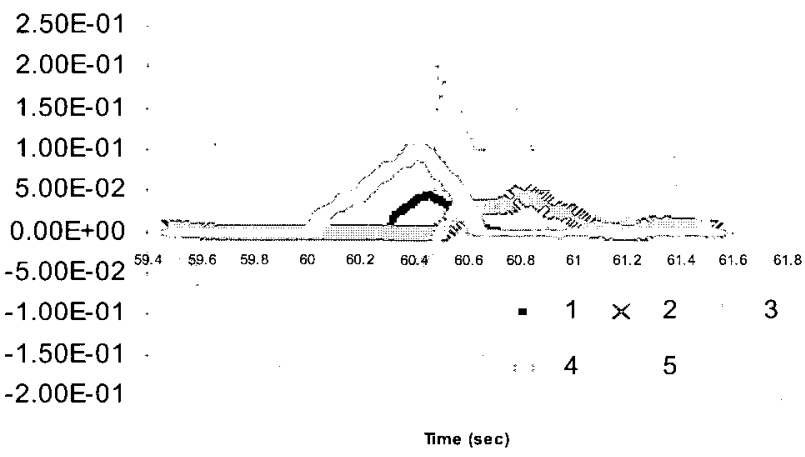

Fig. 14 phase relations of green water impact at the deck structure at wave period $2.0 \mathrm{~s}$ and height $0.5 \mathrm{~m}$ ( 1 represents water onto deck in $\mathrm{m}, 2$ water height $0.37 \mathrm{~cm}$ from the structure in $\mathrm{m}, 3$ pitch motion in radian, 4 freeboard exceedance in $\mathrm{m}, 5$ force at structure in $\mathrm{N} / 10$ )

\subsection{Green water impact on deck structure}

When the waterfront with high velocity hits the superstructure, this causes significant impact loading on the superstructure. Three stages in the loading of the water at the superstructure are identified as follows:

1) impact stage : resulting in the first and highest load. This has the character of an impinging jet or wedge entry. Considering Fig 13, a typical time trace of green water force at the deck structure is shown and the first and highest peak load has a rise time of $0.039 \mathrm{sec}(0.289$ 
sec in full scale). Also see the wedge-typed wave elevation at $71.2371 \mathrm{sec}$ in Fig.11. The impact stage force is normally bigger than the second peak force, thus, more effort should be made for the design purpose. The similar explanation can be made in Fig 12 and 14 for long wave.

2) quasi-static load stage : occurring as soon as most of the kinetic energy of the fluid has been dissipated. A large amount of water has been built up in front of the structure at this stage.

3) plunging water stage : occurring when the water built up in front of the structure falls back onto the deck. This can result in a secondary maximum in the pressure

\section{Conclusion}

Green water phenomena were explained using the tested data carried out in Marintek, Norway. The types of green water are usually known as the dam breaking one and the plunging wave one. In this paper the typical sequence of the dam breaking type was identified in regular waves. In order to analyse green water problems, the top priority should be put on the physical understanding and furthermore the exact numerical technique should be followed for the relative motions, which is one of main inputs to the flow simulation. The motions of the vessels also should be considered in the simulation because the flow may affect the vessel or vice versa.

\section{References}

[1] Buchner B.Green water on Ship-type Offshore Structures,"PhD thesis at Marin, Netheland, 2002

[2] Ersdal G. and Kvitrud A.,"Green water on Norweign Production Ships," Proc. The 10th ISOPE conference, Seattle, WA, USA, 2000

[3] Macgregor J.R., Black F., Wright D. and Gregg J. "Design and Construction of the FPSO vessel for the Schielhallion field,"Trans, the Royal Institution of Naval of Architects, London, UK, 2000

[4] Morris WDM, Miller J. and Buchner B. "Green water Susceptibility of North Sea FPSO/FSUs," 15th conf. Floating Prod. Systems, London, 2000

[5] Stoker J.J Water Waves, The Mathematical Theory with Application, Intercourse Publishers Inc.

Received 31 July 2004

Accepted 10 September 2004 